\title{
Comparison of different chromatin staining techniques for bull sperm
}

\author{
Katarzyna Andraszek', Dorota Banaszewska², Magdalena Czubaszek', Ewa Wójcik and \\ Małgorzata Szostek ${ }^{1}$
}

'Department of Animal Genetics and Horse Breeding, '2Department of Breeding Methods and Poultry and Small Ruminant Breeding, Institute of Bioengineering and Animal Breeding, University of Natural Sciences and Humanities, Siedlce, Poland

\begin{abstract}
Morphological analysis of semen is a very important step in fertility assessment, but many semen defects are not detectable at the morphological level. These include pathological changes in sperm chromatin structure. During mammalian spermiogenesis, histone proteins associated with DNA structure are replaced by specific protamines, with which chromatin does not form nucleosomal complexes. In the fully developed, mature sperm, the histones are replaced with protamines. Disruptions of nucleoprotein structure can be treated as possible indicators of the biological value of spermatozoa. The experimental material consisted of sperm from one-and-a-half-year-old bulls, isolated post mortem from the tail of the epididymis. The smears were stained with silver nitrate $\left(\mathrm{AgNO}_{3}\right)$, acridine orange $(A O)$, aniline blue $(A B)$ and chromomycin $A 3$ (CMA3). Sperm dimensions largely depend on individual variability among the bulls. In most cases, differences in sperm dimensions were identified between individuals, which was confirmed in the statistics. Sperm with elevated, abnormal histone levels were proportionally quite scarce (1.4\%). Studies of nuclear proteins in the context of infertility demonstrate the important influence of normal chromatin structure on sperm functions.
\end{abstract}

Keywords: bull, spermatogenesis, sperm, protamine, histone

Abbreviations: $\mathrm{AB}$ : aniline blue, $\mathrm{AgNO}_{3}$ : silver nitrate, $\mathrm{AO}$ : acridine orange, $\mathrm{CMA3}$ : chromomycin $\mathrm{A} 3$

Archiv Tierzucht 57 (2014) 13, 1-15

doi: $10.7482 / 0003-9438-57-013$

Corresponding author:

Katarzyna Andraszek, email: andrasz@uph.edu.pl

Department of Animal Genetics and Horse Breeding, Institute of Bioengineering and Animal Breeding, University of Natural Sciences and Humanities, Prusa 14, 08-110 Siedlce, Poland

() 2014 by the authors; licensee Leibniz Institute for Farm Animal Biology (FBN), Dummerstorf, Germany. This is an Open Access article distributed under the terms and conditions of the Creative Commons Attribution 3.0 License (http://creativecommons.org/licenses/by/3.0/).
Received: 25 October 2013 Accepted: 29 April 2014 Online: 23 May 2014 


\section{Introduction}

Animal breeding and related problems have in recent years become one of the principal subjects of study for researchers and scientists. Growing population numbers worldwide have led to an increase in the consumption not only of plant foodstuffs, but also, perhaps to an even greater degree, of animal products. For this reason the need has arisen to enhance the efficiency of farm animal reproduction.

Reproduction is closely linked to semen quality and normal sperm structure. The most important element of sperm ultrastructure is the cell nucleus, as fertilisation efficacy depends on its having a normal structure. The sperm cell nucleus is largely filled with DNA, which accounts for about $40 \%$ of its dry matter mass. A bull spermatozoon contains 3.44 pg DNA/ nucleus (Bielańska-Osuchowska \& Sysa 1998, Bochenek et al. 2001). Spermatozoa are haploid cells, and the chromosomes contained in them are monochromatid structures. Owing to differences in mass between cells that contain $\mathrm{X}$ or $\mathrm{Y}$ sex chromosomes, male gametes can be separated in order to select the sex of the offspring (Johnson et al. 1987, Gledhill 1988)

Semen analysis is a multi-staged process. The first step is evaluation of motility, the number of sperm and the proportions of live and dead sperm (Guzick et al. 2001, Hidalgo et al. 2006). The next step is morphological evaluation, which is increasingly expanded to include detailed morphometry of the spermatozoon (Oral et al. 2002). There are situations, however, in which a motile and morphologically normal spermatozoon is incapable of fertilisation, e.g. due to acrosomal defects or abnormalities at the chromatin level (Bianchi et al. 1996, Iranpour et al. 2000). Many semen defects are not detectable at the morphological level. For this reason basic semen analysis should be expanded to include cytogenetic and molecular techniques, mainly to determine in vivo and in vitro fertility. Particularly in the case of assisted reproduction techniques and cryoconservation of sperm, their quality is of immense importance (De Vos et al. 2003, Nagvenkar et al. 2005).

In mammalian spermiogenesis, histone proteins associated with DNA structure are replaced by specific protamines with which chromatin does not form nucleosomal complexes (BielańskaOsuchowska \& Sysa 1998, Zhang et al. 2006). Histones are proteins containing considerable numbers of positively charged amino acids (lysine and arginine) that enable strong bonding between these proteins and the negatively charged double DNA helix (Mudrak 2005, Oliva $\&$ Castillo 2011). In a fully developed, mature spermatozoon, the histones are replaced with protamines. The elimination of the histones gradually progresses throughout spermatogenesis. Histone replacement with protamines, which are half their size, results in a complete change in chromatin organisation between the spermatocyte and the spermatozoon (Balhorn 2011, Oliva \& Castillo 2011). It has been observed in several species that a small fraction of the semen genome is compacted by histones. This histone fraction, currently believed to be present in the sperm of all mammals, is relatively small, constituting no more than $1 \%$ of the genome. The fraction is much larger in humans, probably within the range of 10-15\% (Arpanahi et al. 2009). In bulls, on the other hand, the histone fraction in the sperm nucleus is less than $1 \%$ (Tovich \& Oko 2003). There is much evidence to suggest that such distribution of genes in regions organised by protamines and those organised by histones is not accidental. Such location of sperm genes has recently been presented by two independent teams, using micromatrices and deep genome sequencing technology, respectively (Balhorn 2011, Oliva \& Castillo 2011). 
Protamines are relatively small proteins. Their molecules are composed of 27-65 amino acids rich in arginine and cysteine, with a markedly alkaline $\mathrm{pH}$ (Balhorn 2011). Protamines present in mammalian sperm are of two types: P1 and P2. The former are smaller proteins present in the sperm of all mammals. In eutherian mammals they consist of a single-chain peptide containing only 50 amino acids. A well-known exception in this group is the stallion, which has 51 amino acids (Balhorn et al. 1988, Balhorn 2007). P2 is slightly larger than P1. It contains 63 amino acids in mice. It is only present in eutherian mammal spermatids that are in the process of differentiation (Corzett et al. 2002). In contrast to P1, P2 is synthetised as a larger precursor protein, binds with DNA, and is truncated over the next several days. P2 also contains a large number of cysteine residues that participate in the formation of bisulphide bonds (Corzett et al. 2002, Balhorn 2011).

Abnormal protamine levels in infertile patients were described over 20 years ago (De Yebra \& Oliva 1993, De Yebra et al. 1993). Subsequent studies only confirmed the relationship between an abnormal protamine level and anomalous semen parameters and infertility in men (Evenson et al. 2000, Aoki et al. 2005). The types of protamine anomalies identified involve lower levels of protamines with respect to other proteins, and the P1-P2 transformation index. One possible reason for the excessive P1-P2 ratio observed in some infertile men was found with the identification of P2 transformation and elevated protamine precursor levels in the subgroup of infertile individuals. Moreover, protamine expression may be affected by thermal stress (Balhorn et al. 1988, Aoki et al. 2005, Oliva \& Castillo 2011). A temperature affecting stallion testes may lead to a reduction in the number of bisulphide bonds inserted in the protamines (Love \& Kenney 1999).

The importance of basic proteins stabilising DNA structure has been particularly stressed in recent years. Using cytochemical methods it is possible to identify the change of histonelike proteins present in spermatids into stable protamine proteins in sperm. In certain cases, the direct cause of infertility is disorders in the protein transformation processes during spermiogenesis. Hence, the changes are epigenetic rather than molecular and are associated with DNA structure. Furthermore, nucleoprotein structure disruptions can be treated as possible indicators of the biological value of sperm (Meistrich et al. 2003, Martianov et al. 2005, Enciso et al. 2011). The assessment of chromatin compaction within a spermatozoon not only indicates whether spermatogenesis is normal, but can also provide information about the condition of the paternal genome and epigenome.

The aim of the present study was to identify proteins that stabilise sperm structure and to provide an in-depth analysis of bull sperm morphology using different staining methods.

\section{Material and methods}

The experimental material consisted of sperm from one-and-a-half-year-old bulls, isolated post mortem from the tail of the epididymis. The material was collected from 20 Polish Holstein-Friesians of the Black-and-White variety. The material for the study was obtained during slaughter at a facility where each stage of processing was subject to veterinary control and met European Union requirements, as well as the requirements of the National Ethics Committee for Animal Experiments of the European Union (authorisation number 37/2011).The spermatozoa were isolated according to a method described by Evans et al. (1964), routinely 
used for isolating meiotic chromosomes, modified by Andraszek \& Smalec (2011). Fixed cells were suspended in a small volume of fresh Carnoy's solution, spread over degreased and refrigerated slides and dried at room temperature. The smears were stained with silver nitrate $\left(\mathrm{AgNO}_{3}\right)$, acridine orange (AO), aniline blue (AB) and chromomycin A3 (CMA3). All chemicals for sample preparation were of the highest commercially available purity and were obtained from Sigma-Aldrich Co. LLC. (Poland). The sperm cells were analysed with an Olympus BX50 fluorescence microscope (Olympus, Tokyo, Japan). The MultiScan image analysis system and measurement software from Computer Scanning Systems (Warsaw, Poland) were used for computer analysis of the smears.

\section{$\mathrm{AgNO}_{3}$ staining}

The smears were dyed with an $\mathrm{AgNO}_{3}$ solution following Howell \& Black's (1980) method, modified by Andraszek \& Smalec (2011). The smears were examined microscopically using immersion lenses with a 100x zoom on an Olympus BX50 light microscope. In each smear, morphometric measurements were performed on 30 randomly selected morphologically well-formed spermatozoa, well visible in the field of vision of the microscope, according to a method devised by Kondracki et al. $(2006,2012)$. A total of 600 spermatozoa were examined. The following morphometric measurements were made: sperm head length, sperm head width, sperm head perimeter, sperm head area, perimeter and area of the acrosomal part of the sperm head, sperm mid-piece length, sperm tail width and total sperm length. Based on these measurements, morphological structure parameters of the spermatozoa were computed as well. The data were arranged with reference to particular bulls in order to compare the morphometric sperm traits of individual animals.

\section{Acridine orange staining}

The staining was carried out according to a procedure described by Tejada et al. (1984). The microscopic analysis of the smears included identification of spermatozoa with normal DNA structure (green fluorescence) and those with damaged, single-strand DNA (orange fluorescence). 100 spermatozoa from each animal were analysed, for a total of 2000 spermatozoa.

\section{Aniline blue staining}

The staining was carried out following the procedure described by Franken et al. (1999), with a modification proposed by Wong et al. (2008) to enhance sperm pigmentation. We looked for sperm with histone levels that were normal (light blue colour) and too high (intensive blue colour). 100 spermatozoa from each animal were analysed, for a total of 2000 spermatozoa.

\section{Chromomycin A3 staining}

The smears were stained according to Lolis et al. (1996). We analysed the percentage of spermatozoa with normally compacted chromatin (subdued green fluorescence) and abnormally packed chromatin (intensive green fluorescence). 100 spermatozoa from each animal were analysed, for a total of 2000 spermatozoa. 


\section{Statistical analysis}

The results were statistically processed using analysis of variance according to the following mathematical model:

$$
Y_{i j}=\mu+a_{i}+e_{i j}
$$

where $Y_{i j}$ is the trait value, $\mu$ is the population mean, $a_{i}$ is the bull effect and $e_{i j}$ is the error. The significance of between-group differences was verified using Tukey's test at $P \leq 0.05$ or $P \leq 0.01$. All statistical analyses were performed in STATISTICA 10.0 (StatSoft, Inc. Tulsa, OK, USA).

\section{Results}

The material fixed on the slides was stained using four methods involving chemical agents with different properties. The following subsections present the sperm staining results obtained using the techniques described in »Material and methods«.

\section{$\mathrm{AgNO}_{3}$ staining}

The sperm stained with silver nitrate took on different colours, enabling identification of particular structural elements of their morphology (Figure 1). In the sperm head, the light acrosomal region (a) and dark distal cap (b) were clearly differentiated. The light mid-piece (c) of the tail (d) clearly contrasted with the rest of the tail. This pigmentation made it possible to carry out detailed measurements.

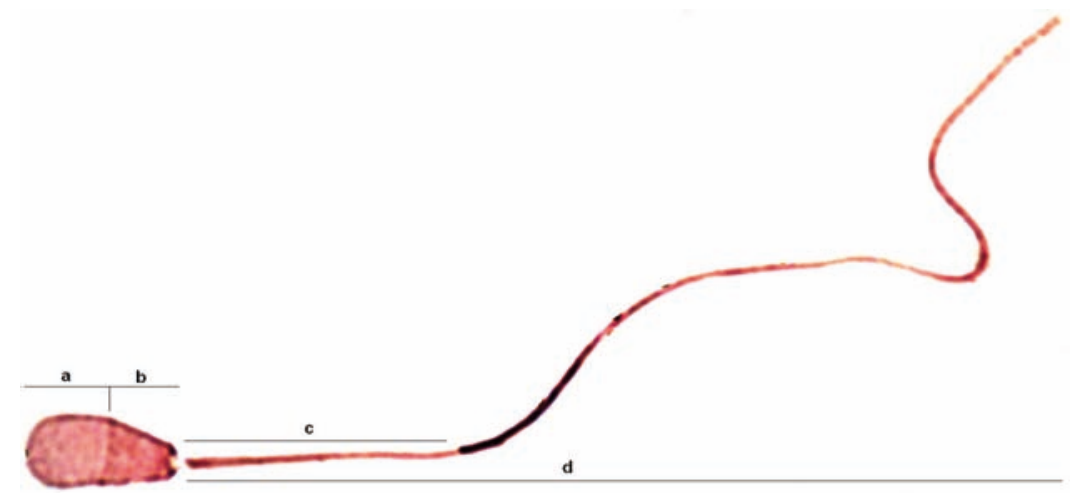

a: acrosomal part, b: distal postacrosomal region (cap), c: mid-piece, d: tail

Figure1

Bull spermatozoon stained with $\mathrm{AgNO}_{3}$

Table 1 contains data on the morphometric parameters of each bull analysed. The data show that the sperm dimensions depended largely on individual variation in the bulls. In most cases, differences were identified in sperm dimensions between individual animals, which was confirmed by the statistics. Sperm dimensions in individual bulls were highly variable. The mean sperm head length ranged from $10.00 \mu \mathrm{m}$ (in bull no. 6) to over $10.50 \mu \mathrm{m}$ (bulls 1 , 


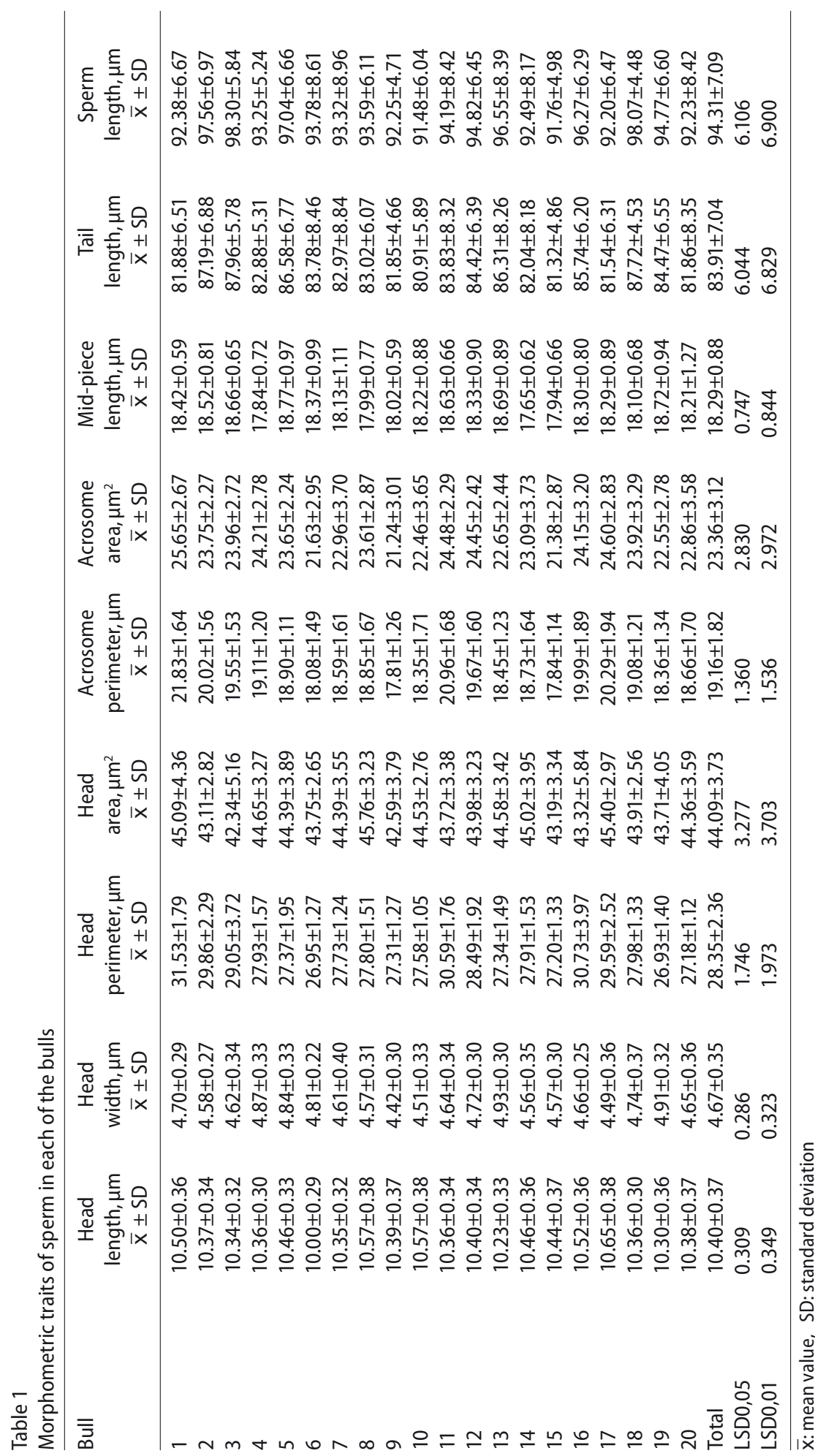


10,16 and 17) $(P \leq 0.01)$. In some cases bulls whose sperm had shorter heads (no. 6, 13 and 19) at the same time produced sperm with slightly broader heads (over $4.80 \mu \mathrm{m}$ ) than those of the other bulls, which additionally reveals certain differences in sperm head shapes. Differences were also found in sperm head perimeter between individual animals. The largest sperm head perimeter was more than $31.5 \mu \mathrm{m}$ (bull no. 1), while sperm with smaller perimeters, by as much as $4.60 \mu \mathrm{m}$, were also observed (bull no. 19) $(P \leq 0.01)$. The area of the sperm head was slightly less variable. In the majority of cases, intergroup differences were small and statistically unconfirmed. High variability was noted in the case of acrosome perimeter and area. Certain correlations were observed in some of the bulls. The spermatozoa that had larger head perimeters and areas (bulls no. 1, 11, 16 and 17) also had larger acrosomal perimeters and areas. This was not, however, uniform for all the bulls, which further supports the hypothesis of variability not only within a species or breed, but also at the level of the individual, or even ejaculate-specific differences. This was also confirmed in the case of the mid-piece and tail dimensions. Some bulls were found to have longer mid-pieces, but also longer tails and greater overall sperm length (bulls no. 2, 3, 4), while others did not exhibit this pattern. An example is bull no. 18, whose sperm had long tails of approximately $87.72 \mu \mathrm{m}$, i.e. almost $7 \mu \mathrm{m}$ longer than in some of the other bulls $(P \leq 0.05)$, and greater overall length, but average mid-piece length $(18.10 \mu \mathrm{m})$. The inverse relationship was also noted, in which sperm had relatively long mid-pieces, e.g. $18.72 \mu \mathrm{m}$ (bull no. 19), but tail and overall length at an average level with respect to the other bulls.

In accordance with the methodology, proportions were determined between selected morphological parameters and correlation coefficients were calculated for pairs of traits (Table 2). The morphological parameters were found to be slightly positively or (in three cases) negatively correlated. The highest negative correlation was identified between sperm head length and width $(-0.037)$, while the highest positive correlation was determined between acrosome area and sperm head area (0.399).

Table 2

Shape proportions and correlation coefficients of selected semen parameters

\begin{tabular}{llcc}
\hline \multicolumn{1}{c}{ Feature } & \multicolumn{1}{c}{$\mathrm{b}$} & $\begin{array}{c}\text { Proportion } \mathrm{a} / \mathrm{b} \\
\overline{\mathrm{x}} \pm \mathrm{SD}\end{array}$ & $\begin{array}{c}\text { Correlation coefficient } \\
\mathrm{r}_{\mathrm{ab}}\end{array}$ \\
\hline Head length & Head width & $2.24 \pm 0.19$ & -0.037 \\
Head length & Mid-piece length & $0.57 \pm 0.03$ & 0.021 \\
Head length & Tail length & $0.12 \pm 0.01$ & 0.118 \\
Head length & Sperm length & $0.11 \pm 0.01$ & 0.169 \\
Mid-piece length & Tail length & $0.22 \pm 0.02$ & 0.134 \\
Mid-piece length & Sperm length & $0.19 \pm 0.02$ & 0.134 \\
Acrosome area & Head area & $0.53 \pm 0.08$ & 0.399 \\
Head area & Mid-piece length & $2.42 \pm 0.23$ & 0.075 \\
Head area & Tail length & $0.53 \pm 0.06$ & -0.006 \\
Head area & Sperm length & $0.47 \pm 0.05$ & -0.003 \\
\hline
\end{tabular}

$\overline{\mathrm{X}}$ : mean value, SD: standard deviation 
Analysis of samples stained with acridine orange, aniline blue and chromomycin A3

Acridine orange staining

Acridine orange is used to identify spermatozoa with normal DNA structure and damaged single-strand DNA. When bound with damaged DNA or RNA, or in sites where there is no DNA in the cell (e.g. the sperm tail), the dye emits red or orange fluorescence. Green fluorescence corresponds to a normal double-strand DNA structure. The sperm exhibited green fluorescence in all the smears analysed (Figure 2), indicating that the genetic material of the sperm produced by the bulls was undamaged (Figure 5).

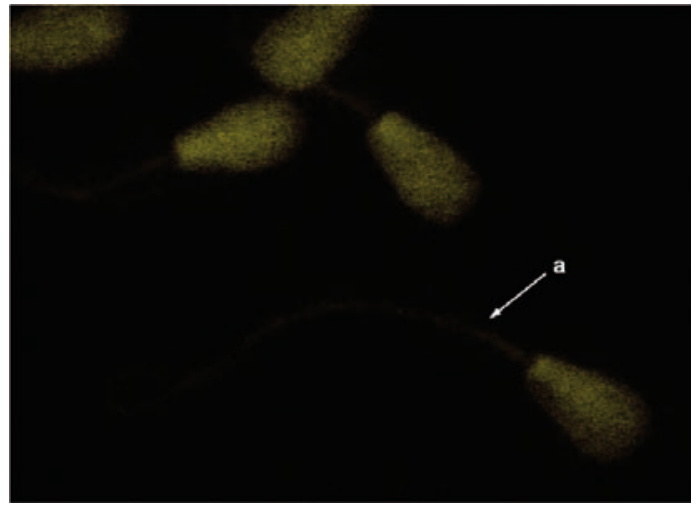

Figure 2

Bull spermatozoa stained with acridine orange; a: normal spermatozoon

Aniline blue staining

Aniline blue enables identification of spermatozoa with normal or abnormal histone retention (Figure 3). Sperm staining revealed mostly sperm with normal histone retention, while sperm with elevated histone levels were proportionally quite scarce (1.4\%) - Figure 5. The highest number of spermatozoa with elevated histone levels was observed in bull 3 .

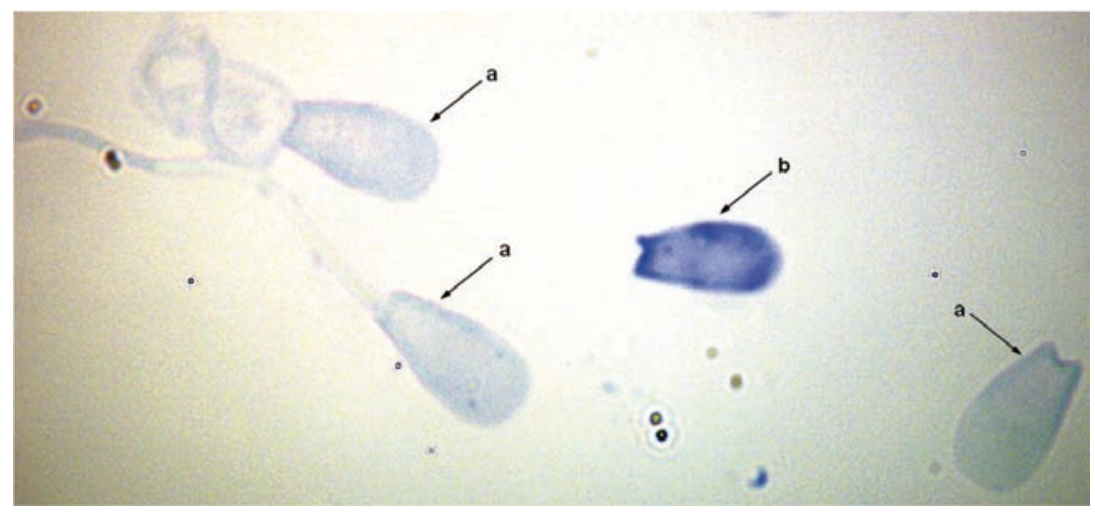

\section{Figure 3}

Bull spermatozoa stained with aniline blue; a: normal spermatozoon, b: spermatozoon with high histone retention 


\section{Chromomycin A3 staining}

Chromomycin A3 staining was used to test chromatin compaction (Figure 4). Five bulls (no. $1,5,14,18$ and 19) were found to have normally compacted chromatin in all the sperm, while the remaining bulls exhibited slight deviations in the number of sperm with normally packed chromatin (Figure 5). The highest number of sperm with abnormally packed genetic material was noted in bull no. 12, for which four defective spermatozoa were identified.

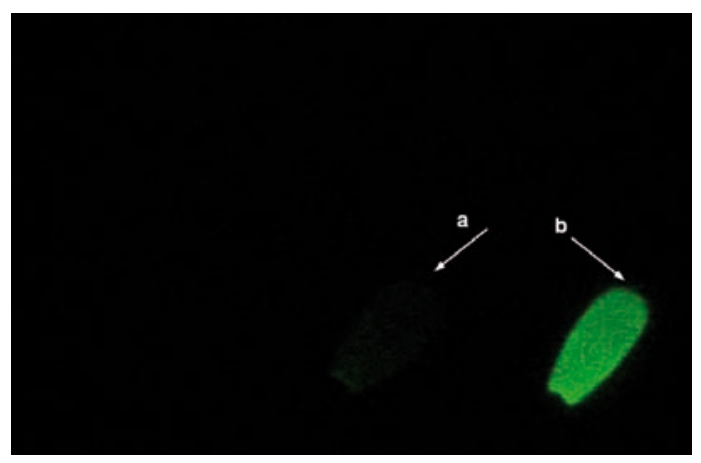

Figure 4

Bull spermatozoa stained with Chromomycin A3; a: normal spermatozoon, b: spermatozoon with anomalous protamination

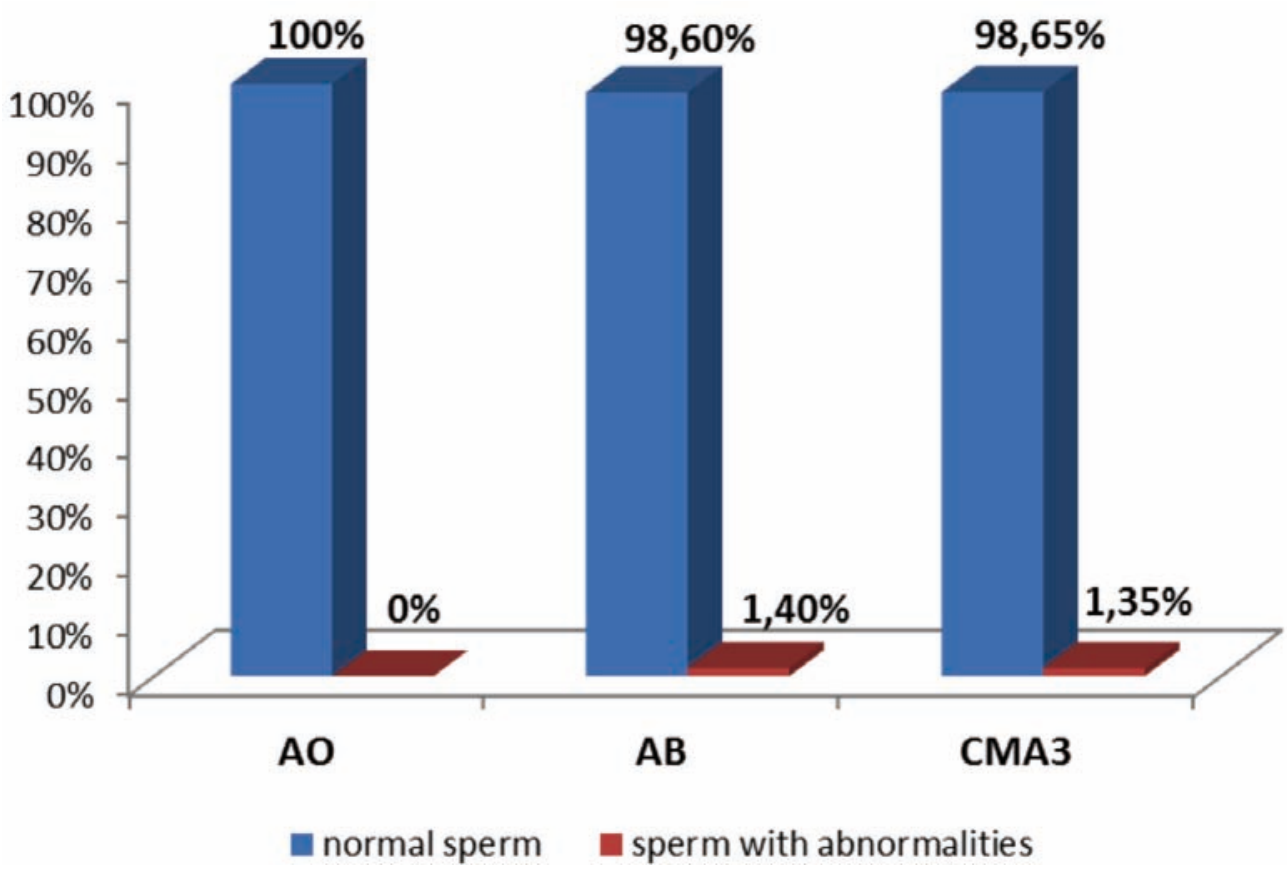

Figure 5

Analysis of smears stained with acridine orange, aniline blue and chromomycin A3 


\section{Discussion}

Standard assessment of the sperm of farm animals consists in detecting morphological anomalies. However, most sperm defects that reduce fertilisation potential are the result of faulty spermatogenesis. These are molecular, cytogenetic and epigenetic changes connected with abnormal chromatin organisation.

Routine assessments of sperm morphology in cattle and pigs predominantly use the eosin-gentian or eosin-nigrosin staining proposed by Hancock (1951). Eosin is particularly recommended for quick evaluation of bull sperm (Chenoweth et al. 1992, Chenoweth 2005, Enciso et al. 2011, Kondracki et al. 2006, 2012). Studies by Kondracki et al. (2006) and Banaszewska et al. (2011) confirm that eosin staining is the standard technique for assessment of sperm morphology in farm animals, commonly applied at animal breeding and insemination centres. Eosin-nigrosin staining is also recommended by WHO as a basic method for evaluating human sperm morphology (Björndahl et al. 2003, 2004). Apart from sperm morphology assessments, this method also enables the identification of living and dead sperm (Sprecher \& Coe 1996, Zambelli \& Cunto 2006, Freneau et al. 2010). Nevertheless, both staining methods allow only for observation of the spermatozoon as a uniform structure and enable measurements of only the sperm head and tail.

Eosin is an acidic dye used to identify alkaline molecules, whereas silver nitrate is a basic pigment applied to detect acidic chromatin proteins, chromatin, nucleolar organisers and nucleoli (Howell \& Black 1980, Andraszek et al. 2009, Andraszek \& Smalec 2011). The use of silver nitrate in sperm morphology assessment has made it possible to identify sperm structures not revealed by eosin. Sperm stained with $\mathrm{AgNO}_{3}$ have differential pigmentation within the head and tail areas and a prominent mid-piece. Sperm head proteins are alkaline, which means that silver nitrate stains the acrosomal part of the head less intensively than the distal part. Silver nitrate staining shows that sperm nucleus chromatin has a different composition in the acrosomal part than in the distal region, which contains acidic proteins and the nucleolus, which reacts positively with silver salts.

Among the tests devised for identification of DNA damage, the most frequently used is acridine orange staining, which enables determination of sperm chromatin stability in an acidic environment. The dye has metachromatic properties. Bound with double-strand DNA, it emits fluorescence in the green band, while bound with RNA and single-strand DNA, it emits red fluorescence. Evenson et al. (1980) found that spermatozoa containing denatured single-strand DNA reduce fertilisation efficacy and the quality of embryos obtained in vitro. Despite the practice of using acridine orange in analyses of sperm of various species, the level of pathological DNA fragmentation has only been defined in humans. A level of up to $15 \%$ spermatozoa with damaged DNA is considered to be a normal state, while a level of 15$25 \%$ reduces fertility and more than $25 \%$ is regarded as representing a high risk of infertility (Evenson et al. 1999, 2000). Similar limits have not been determined for other species. There have been reports of bulls observed to have reduced fertility with over $10 \%$ damaged sperm (Bochenek et al. 2001).

One of the critical moments in spermatogenesis is the replacement of standard chromatinic proteins (histones) with protamines. This reorganisation results in a highly condensed sperm nucleus. Moreover, protamines protect sperm DNA from enzymatic attack by nucleases and 
polymerases. Owing to tight compaction of chromatin by protamines, any changes in or lack of protamines leads to sperm nucleus anomalies and impinges on the morphological quality of semen and its fertilisation capacity. Poor-quality semen is often observed to have chromatin packed too loosely or damaged DNA (Saxena et al. 2008).

Recent years have seen increased interest in the role of sperm histones in semen maturation, fertilisation and early embryonic development. Histones in fertile individuals are linked to micro-RNA promoters and the expression of genes active during embryogenesis (Miller et al. 2010). The histone structure of chromatin in spermatocytes and early spermatogonia enables active transcription. The transcriptional activity of chromatin in mature sperm is inhibited by its protamination. Anomalies in the proportion of histones and protamines within a spermatozoon are correlated with DNA instability, and thus with vulnerability to damage. Higher histone levels have been observed in infertile individuals or those with reduced fertility that have certain anomalies: oligospermia - reduced numbers of mature spermatozoa, teratospermia - spermatozoa with abnormal structure, and asthenozoospermia - anomalous sperm motility (Zhang et al. 2006, Zini et al. 2008). These unique proteins and their possible role in early embryogenesis must be investigated in order to understand the epigenetic factors in male infertility.

Protamines are arginine- and cysteine-saturated proteins. They form an exceptionally condensed and transcriptionally suppressed chromatin conformation in the spermatozoon (Vilfan et al. 2004). The incorporation of protamines $P 1$ and $P 2$ in the mammalian genome is strictly regulated during spermatogenesis. As it turns out, not only anomalous protamination but also the proportions between P1 and P2 affect fertility. Individuals found to have low sperm motility or concentration in morphological analysis exhibit anomalies both in protamination and in P1-P2 proportions. Protamination is indispensable to ensure normal condensation of sperm chromatin, which in turn affects the normal functioning of the sperm (Aoki et al. 2006).

Staining of sperm with $A B$ and $C M A 3$ is a rapid assay to evaluate the quality of chromatin in the sperm. Aniline blue is a dye specific to proteins with high lysine content. Histones, which are replaced with protamines during spermiogenesis, are such proteins. Aniline staining reveals abnormal, excessive histone content in the spermatozoon. Such sperm are more vulnerable to DNA damage and chromatin stability anomalies. Research has shown that early miscarriages and embryonic death are correlated with elevated histone levels in the sperm (Hammadeh et al. 2001, Kazerooni et al. 2009). Chromomycin is a fluorescence dye that specifically binds with guanine-cysteine dinucleotides. Owing to its unique properties, chromomycin can be applied to detect spermatozoa with low chromatin condensation resulting from faulty protamination. However, scientists are cautious about confirming the efficacy of this technique because it becomes targeted at any available G-C dinucleotides. Increased chromomycin availability for these complexes can result from a number of factors. One of them may be DNA damage caused by protamine deficiency, which results in enhanced fluorescence. Although this may be true, researchers still call into question data obtained using this staining method (Hammadeh et al. 2001, Kazerooni et al. 2009).

Some studies have shown that protamine deficiency measured by means of CMA3 staining independently affects fertilisation (Iranpour et al. 2000). Nevertheless, chromatin anomalies within sperm can be present at several levels: histone replacement by protamines, lack of 
protamines, maturation disorders within epididymides, and chromatin stability. Kazerooni et al. (2009) observed that the number of spermatozoa positively stained with CMA3 and $A B$ is greater in individuals with reduced fertility. Since these two assays reveal the quality of the chromatin contained within sperm cells, it can be concluded that the semen of individuals whose parents suffered from spontaneously recurring abortion has low-quality chromatin, specifically with concurrent protamine deficiency. Moreover, sperm vitality and abnormal morphology have been shown to be correlated with the percentage of spermatozoa positively stained with $\mathrm{CMA} 3$ and $\mathrm{AB}$. This indicates that abnormal chromatin compaction has a destructive effect on semen parameters, which is consistent with the observations of other researchers (Coetzee et al. 1998, Hammadeh et al. 1998).

Analysis of protamination disorders is increasingly used to supplement morphological and molecular assessments of semen. Protamination is regarded as an important parameter in the assessment of male fertility (Aoki et al. 2006, Zini et al. 2007). Unfortunately, evaluations of protamination are mainly conducted on human material; this type of analysis of animal sperm is rare and generally limited to laboratory experiments, without practical application. Studies of nuclear proteins in the context of infertility demonstrate the importance of normal chromatin structure for sperm functions. More in-depth understanding of the complex chromatin structure is essential for the development of new, increasingly comprehensive and precise diagnostic tools.

In conclusion, the significance of basic proteins that stabilise the DNA structure of spermatozoa has received particular recognition in recent years. Cytochemical methods make it possible to characterise the change of histone-like proteins present in spermatids into stable protamine proteins in spermatozoa. Certain cases of bull infertility are directly caused by disorders in spermiogenetic protein transformations, not by higher or lower DNA content. Additionally, nucleoproteinic structure anomalies can be regarded as indicative of the biological value of spermatozoa.

\section{References}

Andraszek K, Horoszewicz E, Smalec E (2009) Nucleolar organizer regions, satellite associations and nucleoli of goat cells (Capra hircus). Arch Tierz 52, 177-186

Andraszek K, Smalec E (2011) The use of silver nitrate for the identification of spermatozoon structure in selected mammals. Can J Anim Sci 91, 239-246

Aoki VW, Liu L, Carrell DT (2005) Identification and evaluation of a novel sperm protamine abnormality in a population of infertile males. Hum Reprod 20, 1298-1306

Aoki VW, Liu L, Jones KP, Hatasaka HH, Gibson M, Peterson CM, Carrell DT (2006) Sperm protamine 1/protamine 2 ratios are related to in vitro fertilization pregnancy rates and predictive of fertilization ability. Fertil Steril 86, 1408-1415

Arpanahi A, Brinkworth M, Iles D, Krawetz SA, Paradowska A, Platts AE, Saida M, Steger K, Tedder P, Miller D (2009) Endonuclease-sensitive regions of human spermatozoal chromatin are highly enriched in promoter and CTCF binding sequences. Genome Res 19,1338-1349

Balhorn R (2007) The protamine family of sperm nuclear proteins. Genome Biol 8: 227

Balhorn R (2011) Sperm Chromatin: An Overview. In: Zini A, Agarwal A (eds.) Sperm Chromatin. Biological and Clinical Aplications in Male Infertility and Assisted Reproduction. Springer Science+Business Media, New York, NY, USA, 3-13 
Balhorn R, Reed S, Tanphaichitr N (1988) Aberrant protamine 1/protamine 2 ratios in sperm of infertile human males. Experientia 44, 52-55

Banaszewska D, Kondracki S, Wysokińska A (2011) Effect of age on the dimensions and shape of spermatozoa of Large White Polish boars. Arch Tierz 54, 504-514

Bianchi PG, Manicardi GC, Urner F, Campana A, Sakkas D (1996) Chromatin packaging and morphology in ejaculated human spermatozoa: evidence of hidden anomalies in normal spermatozoa. Mol Hum Reprod 2, 139-144

Bielańska-Osuchowska Z, Sysa P 1998 [Ultrastructure of mammalian sperm]. In: Łukaszczyk A, Bilińska B, Kawiak J, Bielańska-Osuchowska Z (eds.) [The ultrastructure and function of the cell. Mechanisms regulating spermatogenesis]. Wydawnictwo Naukowe PWN Warszawa, Poland, 76-94 [in Polish]

Björndahl L, Söderlund I, Kvist U (2003) Evaluation of the one-step eosin-nigrosin staining technique for human sperm vitality assessment. Hum Reprod 18, 813-816

Björndahl L, Söderlund I, Johansson S, Mohammadieh M, Pourian MR, Kvist U (2004) Why the WHO Recommendations for Eosin-Nigrosin Staining Techniques for Human Sperm Vitality Assessment Must Change. J Androl 25, 671-678

Bochenek M, Smorąg Z, Pilch J (2001) Sperm chromatin structure assay of bulls qualified for artificial insemination. Theriogenology $56,557-567$

Chenoweth PJ (2005) Genetic sperm defects. Theriogenology 64, 457-468

Chenoweth PJ, Spitzer JC, Hopkins FM (1992) A new bull breeding soundness evaluation form. Proc Soc Theriogenology, 63-70

Coetzee K, Kruge TF, Lombard CJ (1998) Predictive value of normal morphology: a structured literature review. Hum Reprod Update 4, 73-82

Corzett M, Mazrimas J, Balhorn R (2002) Protamine 1: Protamine 2 stoichiometry in the sperm of eutherian mammals. Mol Reprod Dev 61, 519-527

De Vos A, Van De Velde H, Joris H, Verheyen G, Devroey P, Van Steirteghem A (2003) Influence of individual sperm morphology on fertilization, embryo morphology, and pregnancy outcome of intracytoplasmic sperm injection. Fertil Steril 79, 42-48

De Yebra L, Oliva R (1993) Rapid Analysis of Mammalian Sperm Nuclear Proteins. Anal Biochem, 201-203

De Yebra L, Ballescà JL, Vanrell JA, Bassas L, Oliva R (1993) Complete selective absence of protamine P2 in humans. J Biol Chem 268, 10553-10557

Enciso M, Cisale H, Johnston SD, Sarasa J, Fernández JL, Gosálvez J (2011) Major morphological sperm abnormalities in the bull are related to sperm DNA damage. Theriogenology 76, 23-32

Evans EP, Breckon G, Ford CE (1964) An Air-Drying Method for Meiotic Preparations from Mammalian Testes. Cytogenetics 3, 289-294

Evenson DP, Darzynkiewicz Z, Melamed MR (1980) Relation of mammalian sperm chromatin heterogeneity to fertility. Science 210, 1131-1133

Evenson DP, Jost LK, Marshall D, Zinaman MJ, Clegg E, Purvis K, de Angelis P, Claussen OP (1999) Utility of the sperm chromatin structure assay as a diagnostic and prognostic tool in the human fertility clinic. Hum Reprod 14, 1039-1049

Evenson DP, Jost LK, Corzett M, Balhorn R (2000) Characteristics of Human Sperm Chromatin Structure Following an Episode of Influenza and High Fever: A Case Study. J Androl 21, 739-746

Franken DR, Franken CJ, De la Guerre H, De Villiers A (1999) Normal sperm morphology and chromatin packaging: comparison between aniline blue and chromomycin A3 staining. Andrologia 31, 361-366

Freneau GE, Chenoweth PJ, Ellis R, Rupp G (2010) Sperm morphology of beef bulls evaluated by two different methods. Anim Reprod Sci 118, 176-181

Gledhill BR (1988) Selection and separation of X- and Y-chromosome bearing mammalian sperm. Gamete Res 20, 377-395 
Guzick DS, Overstreet JW, Factor-Litvak P, Brazil CK, Nakajima ST, Coutifaris C, Carson SA, Cisneros P, Steinkampf MP, Hill JA, Xu D, Vogel DL (2001) Sperm Morphology, Motility, and Concentration in Fertile and Infertile Men. N Engl J Med 345, 1388-1393

Hammadeh ME, Stieber M, Haidl G, Schmidt W (1998) Association between sperm cell chromatin condensation, morphology based on strict criteria, and fertilization, cleavage and pregnancy rates in an IVF program. Andrologia 30, 29-35

Hammadeh ME, Zeginiadov T, Rosenbaum P, Georg T, Schmidt W, Strehler E (2001) Predictive value of sperm chromatin condensation (aniline blue staining) in the assessment of male fertility. Arch Androl 46, 99-104

Hancock JL (1951) A Staining Technique for the Study of Temperature-Shock in Semen. Nature 167, 323-324

Hidalgo M, Rodríguez I, Dorado J (2006) Influence of staining and sampling procedures on goat sperm morphometry using the Sperm Class Analyzer. Theriogenology 66, 996-1003

Howell WM, Black DA (1980) Controlled silver-staining of nucleolus organizer regions with a protective colloidal developer: a 1-step method. Experentia 36, 1014-1015

Iranpour FG, Nasr-Esfahani MH, Valojerdi MR, Al-Taraihi TMT (2000) Chromomycin A3 Staining as a Useful Tool for Evaluation of Male Fertility. J Assist Reprod Genet 17, 60-66

Johnson LA, Flook JP, Look MV (1987) Flow cytometry of $X$ and $Y$ chromosome-bearing sperm for DNA using an improved preparation method and staining with Hoechst 33342. Gamete Res 17, 203-212

Kazerooni T, Asadi N, Jadid L, Kazerooni M, Ghanadi A, Ghaffarpasand F, Kazerooni Y, Zolghadr J (2009) Evaluation of sperm's chromatin quality with acridine orange test, chromomycin $A 3$ and aniline blue staining in couples with unexplained recurrent abortion. J Assist Reprod Genet 26, $591-596$

Kondracki S, Banaszewska D, Wysokińska A, Chomicz J (2006) Sperm morphology of cattle and domestic pigs. Reprod Biol 6 (Suppl.), 99-104

Kondracki S, Banaszewska D, Wysokińska A, Iwanina M (2012) The Effect of Sperm Concentration in the Ejaculate on Morphological Traits of Bull Spermatozoa. Folia Biol (Krakow) 60, 85-91

Lolis D, Georgiou I, Syrrou M, Zikopoulos K, Konstantelli M, Messinis I (1996) Chromomycin A-staining as an indicator of protamine deficiency and fertilization. Int J Androl 19, 23-27

Love CC, Kenney RM (1999) Scrotal Heat Stress Induces Altered Sperm Chromatin Structure Associated with a Decrease in Protamine Disulfide Bonding in the Stallion. Biol Reprod 60, 615-620

Martianov I, Brancorsini S, Catena R, Gansmuller A, Kotaja N, Parvinen M, Sassone-Corsi P, Davidson I (2005) Polar nuclear localization of $\mathrm{H} 1 \mathrm{~T} 2$, a histone $\mathrm{H} 1$ variant, required for spermatid elongation and DNA condensation during spermiogenesis. Proc Natl Acad Sci U S A 102, 2808-2813

Meistrich ML, Mohapatra B, Shirley CR, Zhao M (2003) Roles of transition nuclear proteins in spermiogenesis. Chromosoma 111, 483-488

Miller D, Brinkworth M, lles D (2010) Paternal DNA packaging in spermatozoa: more than the sum of its parts? DNA, histones, protamines and epigenetics. Reproduction 139, 287-301

Mudrak O, Tomilin N, Zalensky A (2005) Chromosome architecture in the decondensing human sperm nucleus. J Cell Sci 118, 4541-4550

Nagvenkar P, Zaveri K, Hinduja I (2005) Comparison of the sperm aneuploidy rate in severe oligozoospermic and oligozoospermic men and its relation to intracytoplasmic sperm injection outcome. Fertil Steril 84, 925-931

Oral E, Yetis O, Elibol F, Senol H, Irez T, Aksu FM (2002) Assessment of human sperm morphology by strict criteria: Comparison of wet preparation versus stained with the modified Diff-Quik method. Arch Androl $48,307-314$

Oliva R, Castillo J (2011) Sperm Nucleoproteins. In: Zini A, Agarwal A (eds.) Sperm Chromatin. Biological and Clinical Aplications in Male Infertility and Assisted Reproduction. Springer Science+Business Media, New York, NY, USA, 45-53

Saxena P, Misro MM, Chaki SP, Chopra K, Roy S, Nandan D (2008) Is abnormal sperm function an indicator among couples with recurrent pregnancy loss? Fertil Steril 90, 1854-1858 
Sprecher DJ, Coe PH (1996) Differences in bull spermiograms using eosin-nigrosin stain, feulgen stain, and phase contrast microscopy methods. Theriogenology 45, 757-764

Tejada RI, Mitchell JC, Norman A, Marik JJ, Friedman S (1984) A test for the practical evaluation of male fertility by acridine orange $(A O)$ fluorescence. Fertil Steril 42, 87-91

Tovich PR, Oko RJ (2003) Somatic Histones Are Components of the Perinuclear Theca in Bovine Spermatozoa. J Biol Chem 278, 32431-32438

Vilfan ID, Conwell CC, Hud NV (2004) Formation of Native-like Mammalian Sperm Cell Chromatin with Folded Bull Protamine. J Biol Chem 279, 20088-20095

Wong A, Chuan SS, Patton WC, Jacobson JD, Corselli J, Chan PJ (2008) Addition of eosin to the aniline blue assay to enhance detection of immature sperm histones. Fertil Steril 90, 1999-2002

Zambelli D, Cunto M (2006) Semen collection in cats: Techniques and analysis. Theriogenology 66, 159-165

Zhang X, San Gabriel M, Zini A (2006) Sperm Nuclear Histone to Protamine Ratio in Fertile and Infertile Men: Evidence of Heterogeneous Subpopulations of Spermatozoa in the Ejaculate. J Androl 27, 414-420

Zini A, San Gabriel M, Zhang X (2007) The histone to protamine ratio in human spermatozoa: comparative study of whole and processed semen. Fertil Steril 87, 217-219

Zini A, Zhang X, San Gabriel M (2008) Sperm nuclear histone H2B: correlation with sperm DNA denaturation and DNA stainability. Asian J Androl 10, 865-871 